\title{
Rehabilitation of pioglitazone
}

\author{
ROBERT EJ RYDER, ${ }^{1}$ RALPH A DEFRONZO²
}

\section{Background}

In 2012 an editorial in the British Medical Journal stated that "it can confidently be assumed that pioglitazone increases the risk of bladder cancer". ${ }^{1}$ Yet now, the recently announced results of a 10-year study mandated by the FDA have failed to demonstrate any association between pioglitazone and bladder cancer ${ }^{2}$ and, because of its many beneficial effects on glucose homeostasis and potential cardiovascular protective effects, the place of pioglitazone in the treatment of diabetes warrants reconsideration.

During pre-clinical studies, an excess of bladder cancers were found in male but not female rats treated with pioglitazone. ${ }^{3}$ of note, these bladder cancers could be prevented by acidification of the urine which prevents pioglitazone crystal formation. ${ }^{4}$ As a result of the findings in rats, the FDA requested a 10-year study of pioglitazone in humans to assess safety with regard to bladder cancer. ${ }^{5}$ The 8-year data have been published online ${ }^{6}$ and the 10-year results recently were made public. ${ }^{2}$ The main results of this study fail to show any association between pioglitazone and risk of bladder cancer. ${ }^{7}$ Another large, recently reported study involving six populations, including 1.01 million diabetic individuals from six countries across the world, has come to the same conclusion. ${ }^{8}$ Previous studies suggesting a link between pioglitazone and bladder cancer have been re-examined. ${ }^{7}$ The link between pioglitazone and bladder cancer in many of these retrospective observational studies is likely to be explained by the fact that patients treated with pioglitazone in the various databases were different from those not treated with pioglitazone, with whom they were compared, i.e. the pioglitazone-treated patients already were at higher risk of bladder cancer from other causes. ${ }^{7}$ Importantly, major risk factors for bladder cancer, i.e. smoking and proteinuria, were not available for most of these retrospective analyses. Initial concern about a potential link between pioglitazone and bladder cancer was derived from the PROactive study, where an apparent excess of bladder cancers was observed for pioglitazone (14) versus placebo (6, p=NS).7,9-11 The PROactive study investigators concluded that, because most of the bladder cancers occurred during the first year following initiation

City Hospital, Birmingham, UK

2 University of Texas Health Science Center, San Antonio, Texas, USA

Address for correspondence: Dr Bob Ryder

Diabetes and Endocrine Unit, City Hospital, Dudley Road, Birmingham

B18 7QH, UK

E-mail: bob.ryder@nhs.net

Br J Diabetes Vasc Dis 2015:15:46-49

http://dx.doi.org/10.15277/bjdvd.2015.021

\author{
Abbreviations and acronyms \\ CHF congestive heart failure \\ FDA US Food and Drug Administration \\ GLP-1 glucagon like peptide \\ $\mathrm{HbA}_{1 \mathrm{c}} \quad$ glycated haemoglobin \\ MACE major adverse cardiac events \\ PROactive PROspective pioglitAzone Clinical Trial In macroVascular \\ Events study
}

of pioglitazone therapy, the drug could not plausibly be related to the development of bladder cancer. ${ }^{9}$ Further, the total numbers of bladder cancers ( $n=20$ ) was small, making it difficult to draw any meaningful conclusion about the statistically insignificant difference between the treatment groups. It has been suggested that pioglitazone might be a tumour promoter and in this way caused the excess of bladder cancer during the first year of PROactive, ${ }^{12}$ although there is no experimental evidence to support such an effect of pioglitazone. The actual data regarding the number of months into the trial when these bladder cancer cases were diagnosed has been published: most appeared so early into the trial (two cases were diagnosed 13 and 14 days into the trial respectively, one at one month, another at three months and a fifth at four months) that they could not possibly have been related to pioglitazone treatment. ${ }^{10,11}$ Links between pioglitazone and bladder cancer in meta-analyses of randomised controlled trials depend entirely on inclusion of these bladder cancer cases in the first year of PROactive, which we now know could not have been related to pioglitazone. ${ }^{10,11}$ Lastly, and most importantly, the 6-year follow up data of PROactive have been published. ${ }^{13}$ After 6 years there were 23 cases of bladder cancer in the pioglitazone-treated group versus 22 cases in the placebo-treated group. Thus, in 2015, it is highly unlikely that there is any link between pioglitazone and bladder cancer at all in humans. $7,10,11$

\section{New perspectives}

It is timely to reconsider the place of pioglitazone in our therapeutic armamentarium for diabetes. With the cloud of bladder cancer risk removed, it is our opinion that pioglitazone is being under-utilised.7,11 It is the only diabetes agent with evidence to suggest that it reduces cardiovascular risk apart from metformin.7,10,11,14 Indeed, there is considerable evidence for a cardioprotective effect of pioglitazone. ${ }^{10}$ This evidence is particularly strong with regard to reducing risk in those who already have coronary artery ${ }^{15}$ or cerebrovascular ${ }^{16}$ disease, or those with renal impairment. ${ }^{17}$ This is especially pertinent since type 2 diabetic patients have a 2-3 fold increase in cardiovascular events. 
Figure 1. The 'ominous octet' of factors which are responsible for the pathophysiologic disturbances of type 2 diabetes ${ }^{14,31}$

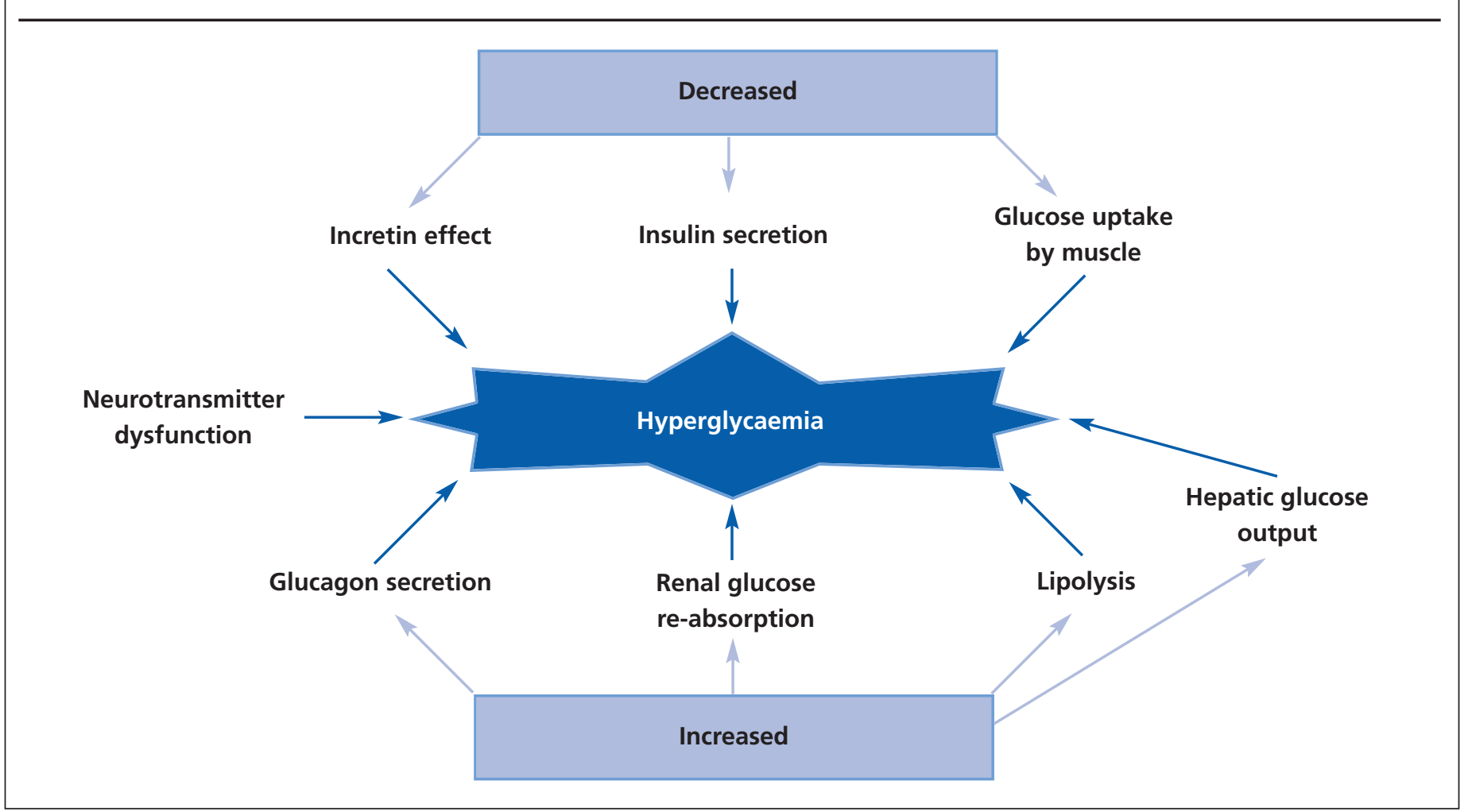

It is often pointed out that the primary composite endpoint in PROactive was not reduced significantly, and the cardiovascular benefit described in this study was based on a pre-specified main secondary endpoint. 9 The failure of the primary composite endpoint to reach statistical significance was accounted for by an increase in leg revascularisation, ${ }^{9}$ which we know is refractory to pioglitazone therapy and which typically is not included in cardiovascular outcome trials. As has been argued in detail, ${ }^{7}$ PROactive's primary outcome might be explained by the impact of pioglitazone acting as an agent of cardiovascular benefit, thereby preventing death, myocardial infarction, acute coronary syndrome, stroke and leg amputation. This would allow diabetic patients to be available for coronary or leg revascularisation and, perhaps, make their arterial vessels more amenable to revascularisation. ${ }^{7}$ Thus, PROactive's primary composite endpoint cannot be relied upon to help in our understanding. ${ }^{7}$ PROactive's main secondary endpoint did not include procedure-based endpoints (for which there were no established criteria), but looked only at MACE (death, myocardial infarction and stroke), revealing a significant cardiovascular benefit of pioglitazone: hazard ratio $=0.84(95 \% \mathrm{Cl} 0.72-0.98, \mathrm{p}=0.027) .^{9}$

The use of statins in patients with diabetes has become more prevalent in the years following the publication of the PROactive study in 2005 (43\% of the PROactive population were taking statin treatment at baseline, despite being at relatively high cardiovascular ris $\left.{ }^{9}\right)$. Increased emphasis on statin treatment in clinical management guidelines has increased statin use in patients with diabetes, which in turn could influence the effect of pioglitazone on clinical outcomes in this population. However, without a dedicated prospective trial we can have no idea whether or not statins combined with pioglitazone would be additive, multiplicative, or less effective with respect to cardiovascular protection. The risk of weight gain, commonly observed in people taking a thiazolidinedione, and an increased risk of distal fractures in women, particularly elderly women, taking pioglitazone need to be weighed against the metabolic and cardiovascular benefits associated with this treatment. As previously reviewed, we believe that this balance is in favour of benefit., 14 With respect to body weight, the greater the weight gain, the greater is the decline in $\mathrm{HbA}_{1 \mathrm{c}}$ and the greater are the increases in $\beta$-cell function and insulin sensitivity. ${ }^{18-20}$

Concern has arisen about the potential to precipitate heart failure in those with underlying diastolic dysfunction, because all thiazolidinediones, including pioglitazone, can cause fluid retention ${ }^{7,11}$ secondary to an effect on the kidney to enhance salt and water reabsorption. ${ }^{21}$ The fluid retention responds well to distally acting diuretics. $^{22}$

It should be emphasised that pioglitazone does not exert any negative inotropic effect on myocardial contractility and improves diastolic dysfunction (ref 23 and DeFronzo, unpublished), reduces blood pressure (afterload), ameliorates myocardial insulin resistance, ${ }^{24}$ improves endothelial dysfunction, and corrects diabetic dyslipidaemia. ${ }^{25}$ The fluid retention associated with pioglitazone treatment is related to the drug's sodium retentive effect on the kidney and recognition of fluid retention (oedema) and institution of diuretic therapy will prevent any cardiac decompensation. ${ }^{26}$ In PROactive the incidence of CHF in pioglitazone-treated subjects was increased. 
However, these cases were not adjudicated and it is noteworthy that individuals with CHF did not experience any increase in mortality: to the contrary, overall mortality and cardiovascular events tended to be decreased.9,26 These results suggest that the cardiovascular benefits of pioglitazone become evident once the excess fluid is diuresed. The sodium retention responds well to distally acting diuretics such as spironolactone or triamterene.

It should be noted that the increased fracture risk is small, the fractures do not involve the hips or spine, are dose related (as are other side effects), primarily occur in postmenopausal females and have not been observed in males or premenopausal females. ${ }^{27,28}$ Therefore, the concern about fractures can be mitigated by not exceeding a daily pioglitazone dose of $30 \mathrm{mg} /$ day and not using pioglitazone in postmenopausal women with a significant decrease in bone mineral density.

Even in patients without known cardiovascular disease, a strong case can be made that the optimum therapeutic combination in the management of type 2 diabetes includes insulin sensitising agents such as pioglitazone and metformin, plus a $\beta$-cell preservation agent such as a GLP-1 receptor agonist. $29-31$ Further, pioglitazone has a potent effect to preserve $\beta$-cell function. 18,30-32 An ominous octet of factors underlying the pathophysiology of type 2 diabetes has been described (Figure 1). ${ }^{31}$ With regard to these eight factors, sulphonylureas augment insulin secretion but this effect is transient and these agents do not preserve $\beta$-cell function. ${ }^{29-31}$ Metformin impacts two members of the ominous octet, while pioglitazone improves four of the abnormalities, and GLP-1 receptor agonists act on five of the eight factors. ${ }^{31}$ Metformin reduces hepatic gluconeogenesis and in muscle it provides an additive effect to pioglitazone in promoting glucose uptake. ${ }^{30,31}$ Pioglitazone reduces hepatic glucose output, increases glucose uptake in muscle, also improves and preserves pancreatic $\beta$-cell function, and is a potent inhibitor of lipolysis. ${ }^{30,31} \mathrm{GLP}$ 1 receptor agonists increase insulin secretion and reduce glucagon secretion, thereby inhibiting hepatic glucose output and also act on the brain, reducing appetite and promoting weight loss. ${ }^{31}$ GLP-1 receptor agonists can, therefore, mitigate the weight increase associated with pioglitazone use. GLP-1 receptor agonists also are natriuretic and minimise the weight gain observed with pioglitazone. ${ }^{29}$ In the pathogenesis of type 2 diabetes, at the stage of impaired glucose tolerance, individuals already have lost more than $80 \%$ of their $\beta$-cell function. ${ }^{31,33} \mathrm{It}$, therefore, can be argued that the optimum management of type 2 diabetes would involve intensive management of the earlier stages using metformin, pioglitazone ${ }^{32,34}$ and GLP-1 receptor agonists, ${ }^{29}$ alone or in combination, with a view to achieving a $\mathrm{HbA}_{1 \mathrm{c}}$ less than $6 \%$ in order to preserve $\beta$-cell function. 18,29-34

In conclusion, in 2015 the accumulated evidence now gives little or no credence to a link between pioglitazone and bladder cancer. At the same time, there is a strong link between pioglitazone and cardiovascular protection. Pioglitazone is and should remain an important agent in the modern paradigm for the optimum management of type 2 diabetic patients, alongside metformin and GLP-1 receptor agonist therapy, especially for those at increased cardiovascular risk.

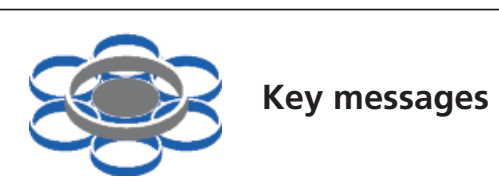

- The therapeutic use of pioglitazone has been limited in recent years due to concerns over bladder carcinogenicity and heart failure

- We now have sufficient data to be confident that there is no association between pioglitazone and bladder cancer

- Moreover, there is considerable evidence that pioglitazone exerts a beneficial effect on cardiovascular risk factors and cardiovascular outcomes, when fluid retention associated with this class of agents is addressed

- Pioglitazone is a potent insulin sensitiser, improves beta cell function, and causes a durable reduction in $\mathrm{HbA}_{1 \mathrm{c}}$

- Pioglitazone is and should remain an important agent within the modern management of type 2 diabetic patients, especially in those at elevated cardiovascular risk

Conflict of interest REJR has received speaker fees, consultancy fees and/or educational sponsorships from Bristol-Myers Squibb/AstraZeneca Alliance, Eli Lilly, GlaxoSmithKline, Janssen, Novo Nordisk, Sanofi-Aventis and Takeda. RAD - Advisory Board: AstraZeneca, Novo Nordisk, Janssen, Lexicon, Boehringer-Ingelheim; Research Support: Bristol Myers Squibb, BoehringerIngelheim, Takeda, AstraZeneca; Speaker's Bureau: Novo-Nordisk, AstraZeneca. Funding None.

\section{References}

1. Hillaire-Buys D, Faillie JL. Pioglitazone and the risk of bladder cancer. BMJ 2012;344:e3500. http://dx.doi.org/10.1136/bmj.e3500

2. Takeda Pharmaceutical Company Limited. Takeda Announces Completion of the Post-Marketing Commitment to Submit Data to the FDA, the EMA and the PMDA for Pioglitazone Containing Medicines Including ACTOS. http://www.takeda.us/newsroom/press_release_detail.aspx? year=2014\&id=314 (accessed 27 March 2015)

3. European Medicines Agency. Assessment report for Actos, Glustin, Competact, Glubrava, Tandemact (INN: Pioglitazone, pioglitazone+ glimepiride, pioglitazone+metformin) 22, December 2011 (EMA,CHMP/940059/2011). Available at http://www.ema.europa.eu/ docs/en_GB/document_library/EPAR_-_Assessment_Report__Variation/human/000285/NC500126656.pdf. (accessed 24 February 2015)

4. Sato $K$, Awasaki $Y$, Kandori $H$, et al. Suppressive effects of acid-forming diet against the tumorigenic potential of pioglitazone hydrochloride in the urinary bladder of male rats. Toxicol Appl Pharmacol 2011;251:23444. http://dx.doi.org/10.1016/j.taap.2011.01.006

5. Lewis JD, Ferrara A, Peng T, et al. Risk of bladder cancer among diabetic patients treated with pioglitazone: interim report of a longitudinal cohort study. Diabetes Care 2011;34:916-22.

http://dx.doi.org/10.2337/dc10-1068

6. Lewis JD, Ferrara A, Strom BL, et al. Cohort Study of Pioglitazone and Bladder Cancer in Patients with Diabetes: Fourth Interim Analysis (8Year) Report with Data from January 1, 1997 to December 31, 2010. May 30, 2012. http://general.takedapharm.com/Trial-Disclosure/01-03TL-OPI524-8-year-Interim-Report.pdf . (accessed 23 December 2014).

7. Ryder REJ. Pioglitazone has a dubious bladder cancer risk but an un- 
doubted cardiovascular benefit. Diabet Med 2015;32:305-13. http://dx.doi.org/10.1111/dme.12627

8. Levin D, Bell S, Sund R, et al. Pioglitazone and bladder cancer risk: a multipopulation pooled, cumulative exposure analysis. Diabetologia 2015; 58:493-504. http://dx. doi.org/10.1007/s00125-014-3456-9

9. Dormandy JA, Charbonnel B, Eckland DJ, et al. Secondary prevention of macrovascular events in patients with type 2 diabetes in the PROactive Study (PROspective pioglitAzone Clinical Trial In macroVascular Events): a randomised controlled trial. Lancet 2005;366:1279-89. http://dx.doi.org/10.1016/S0140-6736(05)67528-9

10. Ryder REJ. Neither evidence from the PROactive study nor the KPNC supports pioglitazone as a tumour promoter. Diabet Med 2015;32:438-9. http://dx.doi.org/10.1111/dme.12703

11. Ryder REJ. Pioglitazone - reports of its death are greatly exaggerated* - it is alive and ready to resume saving lives. Diabet Med 2015;32:e9e15. http://dx.doi.org/10.1111/dme.12736

12. Gale EAM. Pioglitazone: Are rumours of its death exaggerated? Diabet Med 2015;32:431-7. http://dx.doi.org/10.1111/dme.12708

13. Erdmann E, Song E, Spanheimer R, van Troostenburg de Bruyn AR, Perez A: Observational follow-up of the PROactive study: a 6-year update. Diabetes Obes Metab 2014;16:63-74. http://dx.doi.org/10.1111/dom.12180

14. Ryder REJ. Pioglitazone: an agent which reduces stroke, myocardial infarction and death and is also a key component of the modern paradigm for the optimum management of type 2 diabetes. Br J Diabetes Vasc Dis 2011;11:113-20. http://dx.doi.org/10.1177/1474651411412658

15. Erdmann E, Dormandy JA, Charbonnel B, Massi-Benedetti M, Moules IK, Skene AM, Investigators PR: The effect of pioglitazone on recurrent myocardial infarction in 2,445 patients with type 2 diabetes and previous myocardial infarction: results from the PROactive (PROactive 05) Study. J Am Coll Cardio/ 2007;49:1772-80. http://dx.doi.org/10.1016/j.jacc.2006.12.048

16. Wilcox R, Bousser MG, Betteridge DJ, et al, Investigators PR: Effects of pioglitazone in patients with type 2 diabetes with or without previous stroke: results from PROactive (PROspective pioglitAzone Clinical Trial In macroVascular Events 04). Stroke 2007:38:865-73. http://dx.doi.org/10.1161/01.STR.0000257974.06317.49

17. Schneider CA, Ferrannini E, Defronzo R, Schernthaner G, Yates J, Erdmann E. Effect of pioglitazone on cardiovascular outcome in diabetes and chronic kidney disease. J Am Soc Nephrol 2008;19:182-7. http://dx.doi.org/10.1681/ASN.2007060678

18. Gastaldelli A, Ferrannini E, Miyazaki Y, Matsuda M Mari A, DeFronzo RA. Thiazolidinediones improve beta-cell function in type 2 diabetic patients. Am J Phyisol Endocrinol Metab 2007;292:E871-83.

http://dx.doi.org/10.1152/ajpendo.00551.2006

19. Miyazaki $Y$, Mahankali $A$, Matsuda $M$, et al. Effect of pioglitazone on abdominal fat distribution and insulin sensitivity in type 2 diabetic patients. J Clin Endocrinol Metab 2002:87:2784-91. http://dx.doi.org/10.1210/jcem.87.6.8567

20. Miyazaki M, De Filippis E, Bajaj M, et al. Predictors of improved glycaemic control with rosiglitazone therapy in type 2 diabetic patients: a practical approach for the primary care physician. Br J Diabetes Vasc Dis 2005;5: 28-35. http://dx.doi.org/10.1177/14746514050050010601

21. Guan Y, Hao C, Cha DR, et al. Thiazolidinediones expand body fluid volume through PPARgamma stimulation of EnaC-mediated renal salt absorption. Nat Med 2005;11:86-6. http://dx.doi.org/10.1038/nm1278

22. Singh S, Loke YK, Furberg CD. Thiazolidinediones and heart failure - a teleo-analysis. Diabetes Care 2007;30:2148-53. http://dx.doi.org/10.2337/dc07-0141

23. Molina-Wilkins M, Clarke GD, Martinez S, et al. Impaired left ventricular diastolic function (LVDF) is associated with myocardial insulin resistance in patients with type 2 diabetes mellitus (T2DM). Diabetes 2014; 63(suppl 1):A298

24. Molina-Wilkins $M$, Clarke GD, Dong F, et al. Pioglitazone improves myocardial glucose uptake and myocardial blood flow in type 2 diabetic subjects. Diabetes 63 (suppl 1):A237, 2014.

25. DeFronzo RA: Insulin resistance, lipotoxicity, type 2 diabetes and atherosclerosis: the missing links. The Claude Bernard Lecture 2009. Diabetologia 2010;53:1270-87. http://dx.doi.org/10.1007/s00125-010-1684-1

26. Erdmann E, Charbonnel B, Wilcox RG, et al, Investigators PR: Pioglitazone use and heart failure in patients with type 2 diabetes and preexisting cardiovascular disease: data from the PROactive study (PROactive 08). Diabetes Care 2007;30:2773-28. http://dx.doi.org/ 10.2337/dc07-0717

27. Betteridge DJ. Thiazolidinediones and fracture risk in patients with type 2 diabetes. Diabet Med 2011;28:759-71. http://dx.doi.org/10.1111/j.1464-5491.2010.03187.x

28. Bodmer M, Meier C, Kraenzlin ME, Meier CR. Risk of fractures with glitazones: a critical review of the evidence to date. Drug Saf 2009; 32:539-47. http://dx.doi.org/10.2165/00002018-200932070-00001

29. Abdul-Ghani MA, Puckett C, Triplitt C, et al. Initial combination therapy with metformin/pioglitazone/exenatide is more effective than sequential add-on therapy in subjects with new onset diabetes. Results from the Efficacy and Durability of Initial Combination Therapy for Type 2 Diabetes (EDICT): A randomized trial. Diabetes Obes Metab 2015;17: 268-75. http://dx.doi.org/10.1111/dom.12417

30. DeFronzo RA, Eldor R, Abdul-Ghani M. Pathophysiologic approach to therapy in patients with newly diagnosed type 2 diabetes mellitus. Diabetes Care 2013;36(suppl 2):S127-38. http://dx. doi.org/10.2337/dcS13-2011

31. DeFronzo RA. Banting Lecture: from the triumvirate to the ominous octet: a new paradigm for the treatment of type 2 diabetes mellitus. Diabetes 2009;58:773-95. http://dx.doi.org/10.2337/db09-9028

32. DeFronzo RA, Tripathy D, Schwenke DC, et al. Prevention of diabetes with pioglitazone in ACT NOW: Physiologic correlates. Diabetes 2013; 62:3920-6. http://dx.doi.org/10.2337/db13-0265

33. Abdul-Ghani MA, Jenkinson CP, Richardson DK, Tripathy D, DeFronzo RA: Insulin secretion and action in subjects with impaired fasting glucose and impaired glucose tolerance: results from the Veterans Administration Genetic Epidemiology Study. Diabetes 2006;55:1430-5. http://dx.doi.org/10.2337/db05-1200

34. DeFronzo RA, Tripathy D, Schwenke DC, et al. for the ACT NOW Study. Pioglitazone for diabetes prevention in impaired glucose tolerance. NEJM 2011;364:1104-15. http://dx.doi.org/10.1056/NEJMoa1010949 